\title{
Highly Efficient Extraction of Aromatic Compounds from Houttuyniacordata thumb by Cryogenic Grinding Techniques
}

\author{
Qing-Song Xue*
}

\author{
Shanghai Key Laboratory of Green Chemistry and Chemical Process, Department of Chemistry, East China \\ Normal University, Shanghai 200062, China
}

\begin{abstract}
The current study was focused on the extraction of essential oil from Houttuyniacordata thunb (HCT) by using different solvents (ethyl acetate, ethanol, and $n$-hexane) using cryogenic grinding techniques (CGT). The influence of the storage time of the HCT extract on the volatile components was investigated. This paper also discussed and interpreted the mass spectral fragmentation patterns for the three new compounds (undenoyl acetaldehyde, dodenoyl acetaldehyde, and decyl-imine acetaldehyde). The results showed that the extractability of essential oil obtained by CGT using ethyl acetate as an extractant was as high as $1.14 \%$ and the content of decanoyl acetaldehyde in the essential oil was as much as $55.96 \%$, much higher than the previously reported values. It was suggested that the oxidation and decomposition of those unstable components were effectively reduced when the essential oil was extracted by CGT. The content of decanoyl acetaldehyde in the HCT extractant remained constantly when using ethyl acetate as a solvent in the process of storage, while using ethanol as a solvent, the content of decanoyl acetaldehyde decreased rapidly as the storage time increased. The author proposed that the ethanol reacted with decanoyl acetic acid and formed decanoyl acetic ether, which accelerated the decomposition of the decanoyl acetaldehyde.
\end{abstract}

Keywords Houttuyniacordata thumb, cryogenic grinding techniques, essential oil, decanoyl acetaldehyde, mass spectra.

\section{INTRODUCTION}

HCT is widely distributed throughout Southeast Asia [1]. As herb of antibiotic activity, HCT has been a timehonored traditional Chinese medicine (TCM) and widely used for treating anaphylaxis, lung cancer and viral infections [2]. It provides a wide range of pharmacological activities, including antiviral [3], antieukemic [4], antioxidative and antimutagenic effects [5], which are mainly attributed to its volatile oil (or essential oil). Houttuynine (decanoyl acetaldehyde) and 2-undecanone are the predominant components in the essential oil, while their reported contents in the volatile oil are quite different [6-9]. For example, a method of flash gas chromatography indicated a level of decanoyl acetaldehyde of $0.60 \%$ and a level of 2-undecanone of $3.59 \%$ [7], whereas steam distillation (SD) showed those levels to be $5.10 \%$ and $9.84 \%$ [8], and headspace solid-phase microextraction (HS-SPME) showed them to be $7.23 \%$ and $22.21 \%$ [6], respectively. Decanoyl acetaldehyde is unstable and easily oxidized to decanoyl acetic acid and then decomposed into 2-undecanone in the process of distillation or during storage [6], resulting in a lower content of decanoyl acetaldehyde in the HCT essential oil. Therefore, there is a definite need for a highly efficient method of extracting decanoyl acetaldehyde

*Address correspondence to this author at the Shanghai Key Laboratory of Green Chemistry and Chemical Process, Department of Chemistry, East China Normal University, 3663 Zhongshan North Road, Shanghai 200062, China; Tel: (+86) 21-62232753; Fax: (+86) 21-62238510;

E-mail: qsxie@chem.ecnu.edu.cn from HCT samples by reducing the decomposition of decanoyl acetaldehyde.

Cryogenic grinding has long been developed as a traditional technique. It allows volatile oil from the plants to be released thoroughly and immediately, and also significantly reduces the loss of volatile oil [10-12]. What's more, the unstable and easily-oxidized compounds in the volatile oil can be kept free from decomposition and oxidation. To the best available knowledge, there have been no reports of extracting volatile oil from HCT by CGT. Liquid nitrogen at -195.6 ${ }^{\circ} \mathrm{C}$ as a quick-freezing agent can provide the refrigeration needed to pre-cool the HCT sample, further more the vapourisation of the liquid nitrogen creates an inert and dry environment for additional protection of the quality of the HCT. In this paper, the author extracted essential oil from HCT by CGT. The results showed that the extractability of the volatile oil using ethyl acetate as an extractant was as much as $1.14 \%$, and the content of decanoyl acetaldehyde in the extract was as high as $55.96 \%$. Furthermore, a reasonable mechanism for decomposition of decanoyl acetaldehyde during storage of the HCT extractant was presented.

\section{MATERIALS AND METHODS}

\subsection{Materials}

Dr. Teng Xue collected fresh, wild HCT flowers from Changfeng Park, Putuo, Shanghai, China, which were 
then identified by Dr. Wei-Dong Zhang, Shanghai Institute for Food and Drug Control, Shanghai, China. The analytical grade reagents $(99.9 \%)$ of ethyl acetate, ethanol, and $n$-hexane were purchased from Shanghai Chemical Reagent Corporation, Shanghai, China. The researchers purchased liquid nitrogen from Shanghai Lü Min Corporation, Shanghai, China, and $n$-Dodecane (AR, 99.9\%) from Fisher Scientific Corporation, New York, USA.

\subsection{Extraction of the Volatile Compounds}

The HCT essential oil extracted by CGT was prepared as follows: $5 \mathrm{~g}$ of cryogentic ginding HCT sample was obtained by immersing HCT into a container with liquid nitrogen for $5 \mathrm{~min}$ and then grinding it immediately. Then $10 \mathrm{~g}$ of extractant was added to the powder of the cryogentic ginding HCT sample. The mixtures were stirred at room temperature for $30 \mathrm{~min}$.

\subsection{Gas Chromatography-Mass Spectrometry}

The extract with extractant was analyzed using an gas chromatograph with a mass spectrometer (68905973N, Agilent Corporation, Palo Alto, America) and a HP-5MS column (length $30 \mathrm{~m}$, i.d. $0.25 \mathrm{~mm}$, film thickness $0.25 \mu \mathrm{m}$; stationary phase: diphenyl-95\% dimethyl siloxane copolymer). High pure helium $(99.999 \%)$ was used as the carrier gas at a flow rate of $1 \mathrm{~mL} \cdot \mathrm{min}^{-1}$. The oven temperature was programed as follows: a starting temperature of $40^{\circ} \mathrm{C}$, then increased to $120^{\circ} \mathrm{C}$ at a rate of $5{ }^{\circ} \mathrm{C} \cdot \mathrm{min}^{-1}$, at which temperature the column was maintained for $2 \mathrm{~min}$, then to $240^{\circ} \mathrm{C}$ at $8^{\circ} \mathrm{C} \cdot \mathrm{min}^{-1}$. The injection port was maintained at 250 ${ }^{\circ} \mathrm{C}$. The temperature of the interface between $\mathrm{GC}$ and MS was $280^{\circ} \mathrm{C}$. A split injection with a ratio of $6: 1$ was used. The sample volume injected was $1 \mu \mathrm{L}$. The solvent delay was $6.5 \mathrm{~min}$. The mass spectrometer was fitted with an El source operated $70 \mathrm{eV}$ with an ion source temperature of $230{ }^{\circ} \mathrm{C}$ and quadrupole temperature of $150{ }^{\circ} \mathrm{C}$, and mass spectra were recorded in the range $\mathrm{m} / \mathrm{z} 12-550 \mathrm{amu}$ in the full-scan acquisition mode. The mass spectra were matched with a NIST 2002 library.

The content of the components in the extract was calculated by normalizing the peak area on a total ion current chromatogram (TIC) after deduction of the extract. The extractability of essential oil was calculated by internal standard method ( $n$-dodecane as internal standard).

\section{RESULTS AND DISCUSSION}

\subsection{Effect of Extractants on the Components in HCT Essential Oil}

Figure 1 illustrates the GC-MS chromatograms of the HCT essential oil extracted by CGT with different extracts. Table 1 shows the components and their relative proportions (\%, total ion current). Twenty-one volatile components from HCT using acetic ether as an extractant were found and seventeen components were identified by matching with the standard mass spectra in the NIST 2002 library. Among other four unidentified components, the peak area of the component at a retention time of $21.97 \mathrm{~min}$ is too small, resulting in weak signal on the mass spectrum and inability to identify it. As Figure $\mathbf{2 a}$ indicates, the component at a retention time of $22.18 \mathrm{~min}$ can be initially considered to be decanoyl acetaldehyde on the basis of its molecular ion of $198(\mathrm{~m} / \mathrm{z})$. Liang et al. [6] reported on the mass spectra of decanoyl acetaldehyde and analyzed its formation mechanism in detail. There are two $-\mathrm{C}=\mathrm{O}$ with the one on the tip being more active than $-\mathrm{CH}_{3}$ in decanoyl acetaldehyde molecular, making it easy to lose $\mathrm{H}_{2} \mathrm{O}\left(\mathrm{M}^{+}-18\right), \mathrm{CO}\left(\mathrm{M}^{+}\right.$ -28) groups, resulting in a strong abundance of $\mathrm{m} / \mathrm{z}$ 180,170 ions, respectively. The fragments of $m / z 162$, 155,152 are produced when the groups of $\mathrm{H}_{2} \mathrm{O}+\mathrm{H}_{2} \mathrm{O}$ $\left(\mathrm{M}^{+}-36\right), \mathrm{CH}_{2} \mathrm{CHO}\left(\mathrm{M}^{+}-43\right), \mathrm{CO}+\mathrm{H}_{2} \mathrm{O}\left(\mathrm{M}^{+}-46\right)$ are lost,

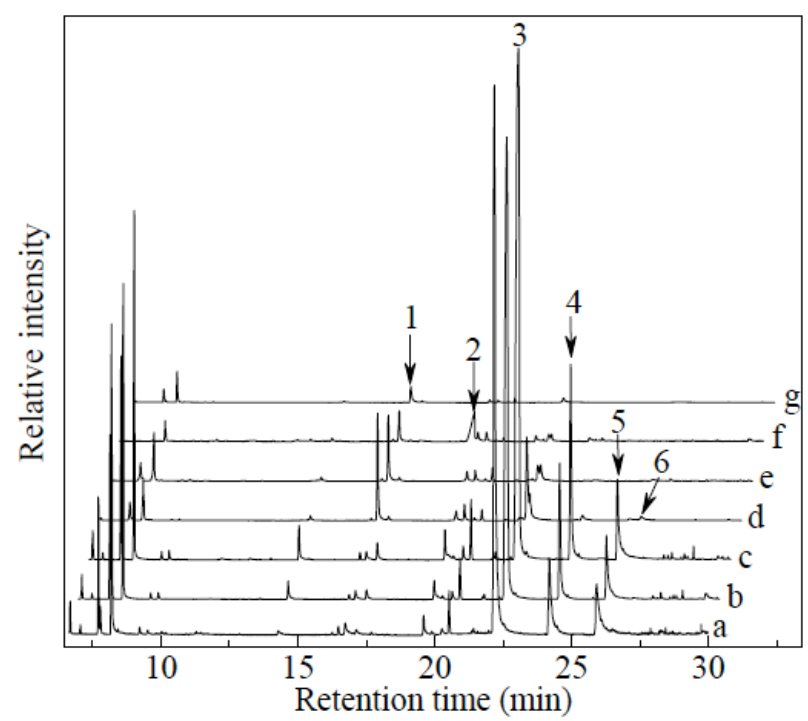

Figure 1: The total ion current chromatogram of HCT essential oil extracted by CGT using acetic ether $(a \sim c)$, ethanol $(\mathrm{d} \sim \mathrm{f})$, n-hexane $(\mathrm{g})$ as extractants. The essential oil with extractant kept at room temperature for $0.5 \mathrm{~h}(\mathrm{a}, \mathrm{d}, \mathrm{g}), 1$ day (b, e), and 18 days (c, f) before GC-MS analysis. 1. 2undecanone; 2 . decanoic acid; 3 . decanoyl acetaldehyde; 4. undenoyl acetaldehyde; 5. dodenoyl acetaldehyde; 6. Decylimine acetaldehyde. 
Table 1: The Main Components of the HCT Essential Oil Extracted by CGT Using Acetic Ether (a c), Ethanol (d f), $n$ Hexane (g) as Extractants

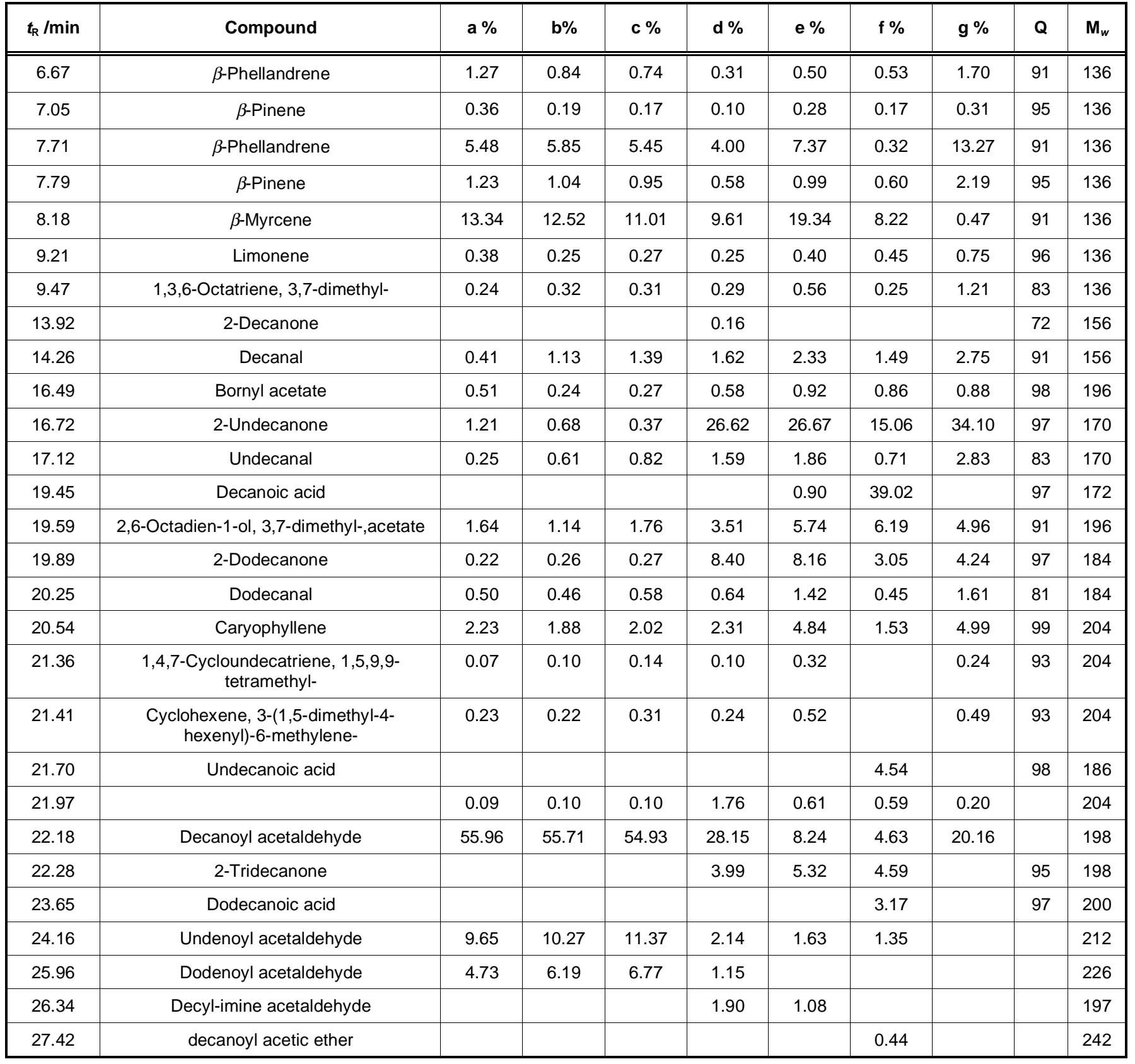

Q: quality $/ \% ; \mathrm{M}_{\mathrm{w}}$ : molecular weight; the series numbers of the samples are the same as in Table 1.

respectively. These fragment ions completely coincide with those of the mass spectrum at a retention time of 22.18 min obtained in this experiment as shown in Figure 2a. This clearly indicates that the component at a retention time of $22.18 \mathrm{~min}$ is decanoyl acetaldehyde. As Figure $\mathbf{2 b}$ and $\mathbf{c}$ indicate, the molecular ions of the two compounds are 212 and 226, respectively. The forming mechanism of fragments in the two mass spectra is very similar to that of decanoyl acetaldehyde. Therefore, it was assumed that the two compounds at a retention time of $24.16,25.96$ min were undenoyl acetaldehyde and dodenoyl acetaldehyde, respectively. As shown in Figure 3, the groups of $\mathrm{H}_{2} \mathrm{O}\left(\mathrm{M}^{+}-18\right)$, $\mathrm{CO}$ $\left(\mathrm{M}^{+}-28\right), \mathrm{CH}_{2} \mathrm{CHO} / \mathrm{CH}_{2} \mathrm{CH}_{3}\left(\mathrm{M}^{+}-43\right), \mathrm{H}_{2} \mathrm{O}+\mathrm{CO}\left(\mathrm{M}^{+}-46\right)$ in the molecular structure of the above-mentioned compounds are easily lost, resulting in the corresponding fragments. A series of fragments (containing keto-carbonyl, such as $m / z$ 150, 138, 124, 110 , etc.) are produced when both the aldehyde and the corresponding alkyl groups are simultaneously lost. What's more, a series of alkyl fragments (such as $\mathrm{m} / \mathrm{z}$ $29,43,57,71,99,113,127$, etc.) are produced when 


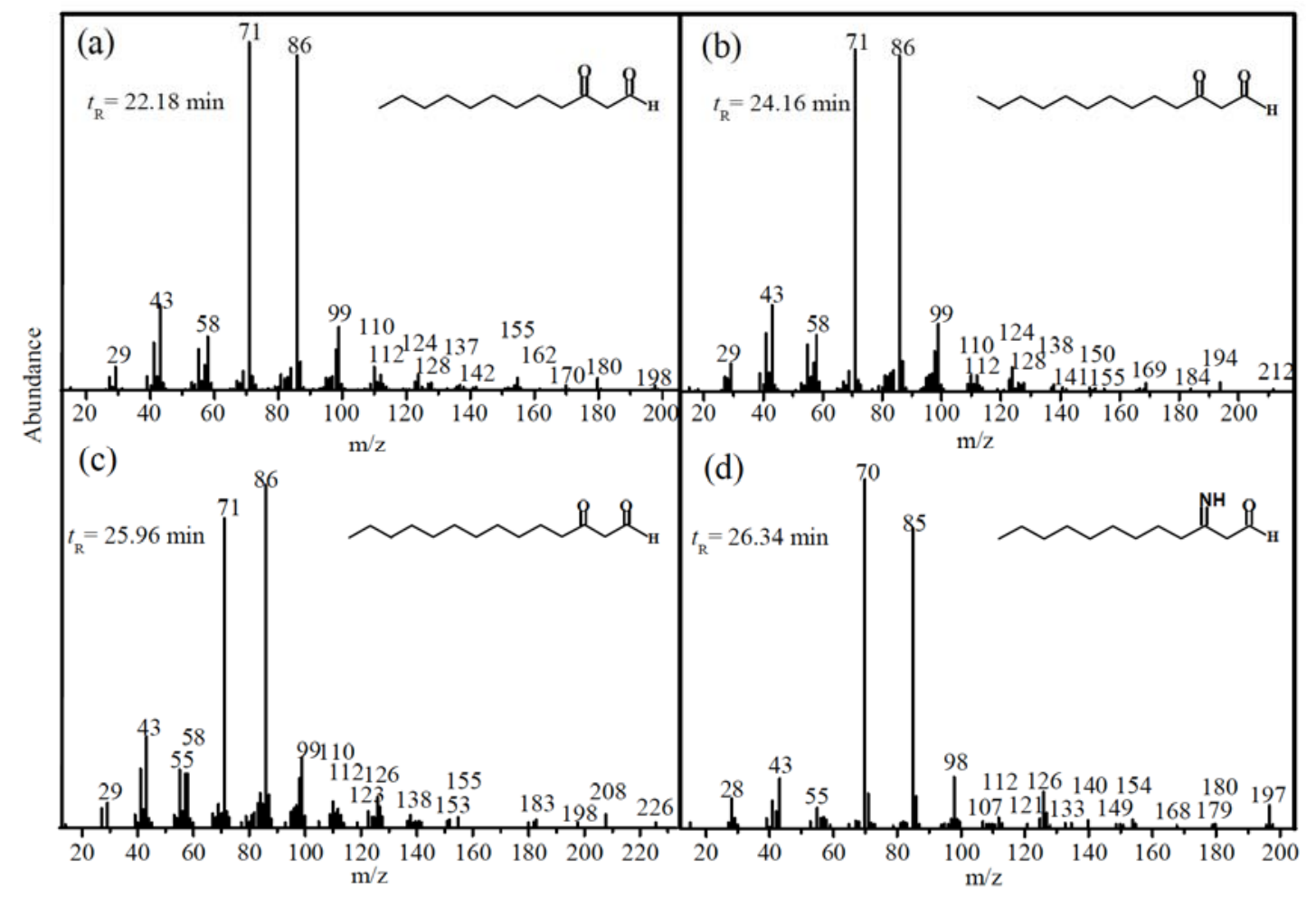

Figure 2: Mass spectra (El, $70 \mathrm{eV}$ ) of HCT sample resolved by GC-MS at a retention time (a) 22.18, (b) 24.16, (c) 25.96, and (d) $26.34 \mathrm{~min}$, respectively.

both the group of $\mathrm{COCH}_{2} \mathrm{CHO}$ and the corresponding alkyl groups are simultaneously lost. The fragment of $\mathrm{m} / \mathrm{z} 71$ is mainly due to the formation of $\mathrm{C}_{5} \mathrm{H}_{11}{ }^{+}$, $\mathrm{CH}_{3} \mathrm{COCH}_{2} \mathrm{CH}_{2}^{+}$, and $\mathrm{COCH}_{2} \mathrm{CHO}^{+}$. The fragment of $\mathrm{m} / \mathrm{z} 86$ is mainly due to the formation of rearranged fragments $\mathrm{CH}_{3}\left(\mathrm{CH}_{2}\right)_{4} \mathrm{CH}_{3}{ }^{+}, \mathrm{CH}_{3} \mathrm{CH}_{2} \mathrm{CHCOCH}_{3}{ }^{+}$, and $\mathrm{CH}_{3} \mathrm{COCH}_{2} \mathrm{CHO}^{+}$. A mass spectrometry analysis further confirmed that the components at a retention time of $24.16,25.96$ min were undenoyl acetaldehyde and dodenoyl acetaldehyde, respectively. To the best of our knowledge, there have been no reports of mass spectra of undenoyl acetaldehyde and dodenoyl acetaldehyde, which is possibly due to the oxidation and decomposition of those compounds during the extraction of the HCT essential oil at higher temperature. The results showed that the CGT extraction method was efficient for extraction of decanoyl acetaldehyde and its homologues from HCT samples.

Notably, decanoyl acetaldehyde (55.96\%) is a predominant component of the HCT essential oil extracted by CGT using acetic ether as an extract, much higher than in that extracted by steam distillation $(5.10 \%)$ [8] and headspace solid-phase microextraction (7.23\%) [6]. Meanwhile, the content of 2undecanone regarded as an oxydate of deacnoyl acetaldehyde in the HCT volatile oil was only $1.21 \%$. The results showed that the oxidation and decomposition of decanoyl acetaldehyde was efficiently reduced when the HCT essential oil was extracted by CGT using acetic ether as an extract under ultra-low temperatures. Furthermore, the content of undenoyl acetaldehyde and dodenoyl acetaldehyde were as much as $9.65 \%$ and $4.72 \%$, respectively. The results showed that the CGT extraction method was accessible and available for highly efficient extraction of decanoyl acetaldehyde and its homologues from HCT samples.

Twenty-four volatile components from HCT extracted by CGT using ethanol as an extractant were found and the components were the same as when acetic ether was used as an extractant, except for the absence of 2-decanone, 2-tridecanone and decyl-imine acetaldehyde. Decyl-imine acetaldehyde was found for the first time in this experiment and has not been reported in literatures. As shown in Figure $\mathbf{2 d}$, the molecular ion of the compound at a retention time of $26.34 \mathrm{~min}$ was 197 . There was only a difference of 1 $(\mathrm{m} / \mathrm{z})$ between the main fragments of $\mathrm{m} / \mathrm{z} 197,179$, $154,98,85,70$, etc. in the mass spectrum at a retention time of $26.34 \mathrm{~min}$ and the corresponding fragments of decanoyl acetaldehyde. Therefore, the 


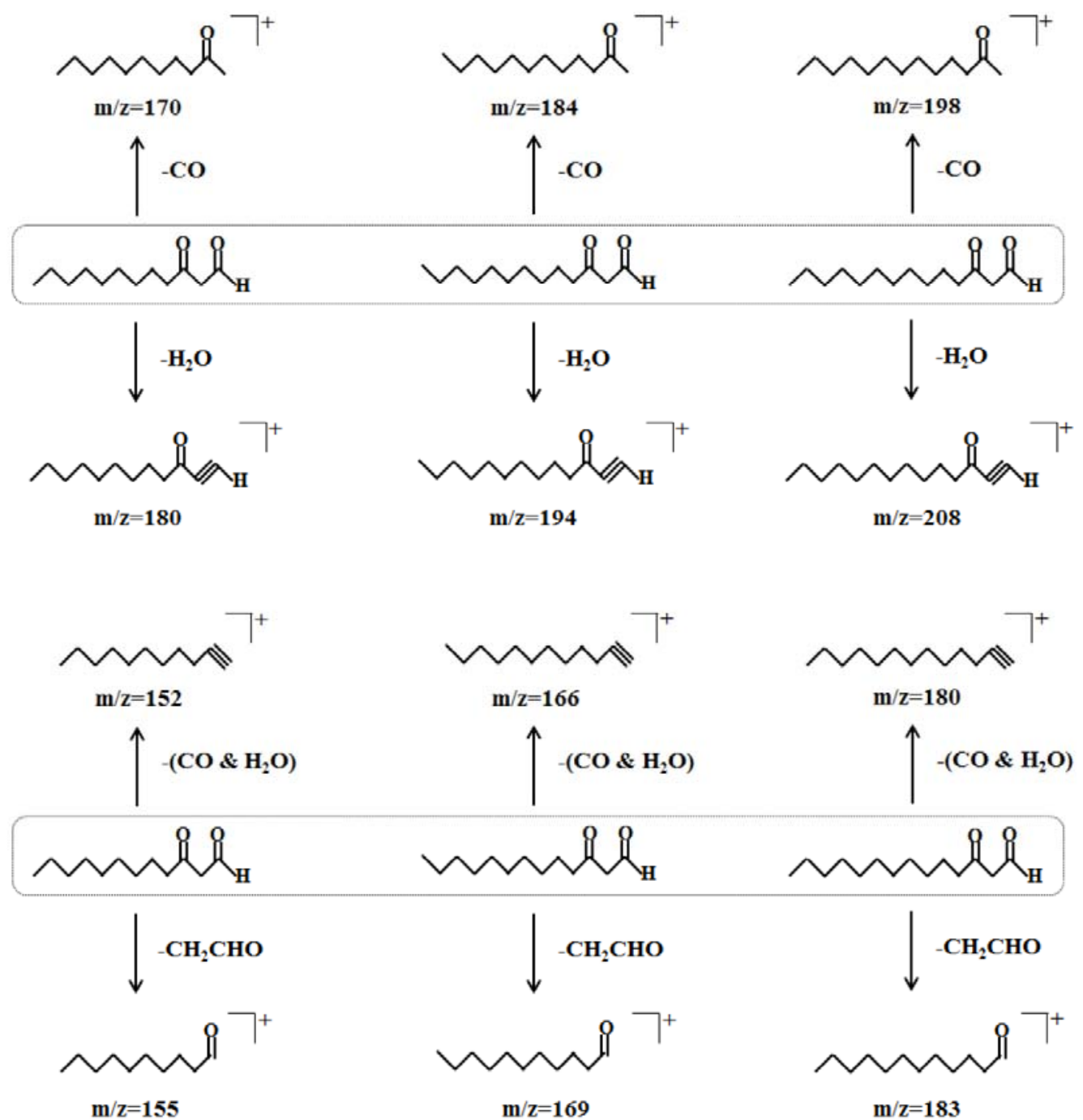

Figure 3: Major fragment ions of decanoyl acetaldehyde, undenoyl acetaldehyde and dodenoyl acetaldehyde.

component at a retention time of 26.34 min can be initially considered to be decyl-imine acetaldehyde. According to the law of mass spectrometry, the groups of $\mathrm{NH}_{3}\left(\mathrm{M}^{+}-17\right), \mathrm{H}_{2} \mathrm{O}\left(\mathrm{M}^{+}-18\right)$ are easily lost, resulting in a strong abundance of $\mathrm{m} / \mathrm{z} 180,179$ ions, respectively. The fragments of $m / z 168,154$, and 126 are produced when the groups of $\mathrm{CHO} / \mathrm{C}_{2} \mathrm{H}_{5}\left(\mathrm{M}^{+}-29\right)$, $\mathrm{CH}_{2} \mathrm{CHO} / \mathrm{C}_{3} \mathrm{H}_{7}\left(\mathrm{M}^{+}-56\right)$, and $\mathrm{HCNHCH}{ }_{2} \mathrm{CHO} / \mathrm{C}_{5} \mathrm{H}_{11}\left(\mathrm{M}^{+}\right.$ -71) are lost, respectively. There are no fragment ions of $\mathrm{m} / \mathrm{z} 162\left(-2 \mathrm{H}_{2} \mathrm{O}, \mathrm{M}^{+}-36\right), 152\left(-\mathrm{H}_{2} \mathrm{O}\right.$ and $-\mathrm{CO}, \mathrm{M}^{+}$$46)$, and $142\left(-2 \mathrm{CO}, \mathrm{M}^{+}-43\right)$ in the mass spectrum at a retention time of $26.34 \mathrm{~min}$, which are considered to be characteristic fragments of decanoyl acetaldehyde. The analysis of mass spectrum further confirmed that the component at a rentention time of $26.34 \mathrm{~min}$ is decylimine acetaldehyde. Furthermore, compared with using acetic ether as an extractant, the content of 2undecanone in HCT essential oil extracted by CGT using ethanol as an extractant remarkably increased to
$26.62 \%$, while the content of decanoyl acetaldehyde markedly decreased to $28.15 \%$ but was still significantly higher than the results of publications $[6,8]$ . The results showed that the CGT extraction method was superior to the methods like steam distillation and headspace solid-phase microextraction.

A series of $n-\mathrm{C}_{19 \sim 28}$ alkanes in the HCT volatile oil extracted by CGT using $n$-hexane as an extractant were found (not illustrated in Figure $\mathbf{1}$ and Table 1), while the other main volatile components were the same as using acetic ether as an extractant, except for the absence of undenoyl acetaldehyde and dodenoyl acetaldehyde. The total content of those alkanes in the volatile oil was $2.65 \%$. Decanoyl acetaldehyde $(20.16 \%)$ and 2-undecanone (34.10\%) were predominant components of the HCT sample obtained by CGT using $n$-hexane as an extractant. Among three extractants, the content of decanoyl acetaldehyde and 
its homologues in the HCT essential oil was as such: acetate ether $>$ ethanol $>n$-hexane. However, the trend in 2-undecanone is opposite.

The effect of extractants on the extractability of HCT essential oil is shown in Figure 4. Clearly, the maximum extractability of essential oil extracted by CGT using acetic ether as an extractant was as high as $1.14 \%$, which was much higher than by steam distillation (0.085\%) [13], and also higher than by solvent immersion at room temperature $(0.29 \%)$ [14]. However, the extractability extracted by CGT using ethanol as an extractant markedly decreased to $0.23 \%$. The lowest extractability extracted by CGT using $n$ hexane as an extractant was only $0.05 \%$. The extractability of 2-undecanone extracted by CGT using $n$-hexane as an extractant showed no obvious distinction from what by CGT using acetic ether as an extractant, although a much higher content of 2undecanone (34.10\%) in HCT essential oil extracted by CGT using $n$-hexane as an extractant was obtained. The results indicates that $n$-hexane is not suitable for the extraction of volatile components from HCT, especially not suitable for the extraction of decanoyl acetaldehyde and its homologues. The extractability of 2-undecanone extracted by CGT using ethanol as an extractant was higher than that using acetic ether as an extractant despite the lower extractability of essential oil using ethanol as an extactant. It was suggested that the ethanol extractant may be either unsuitable for the extraction of decanoyl acetaldehyde from HCT samples or it can accelerate oxidation and decomposition of decanoyl acetaldehyde. The following discussion demonstrates that the latter conjecture is more reasonable.

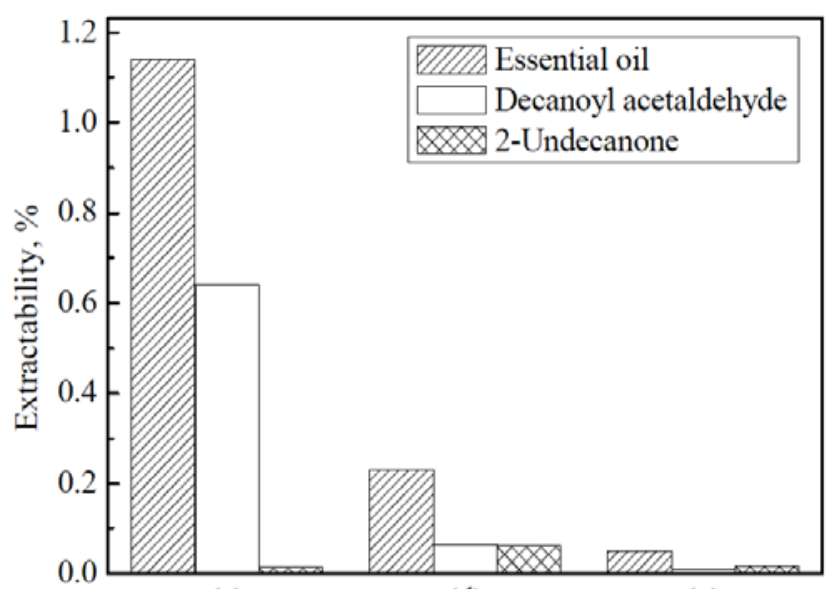

(a)

(d)

(g)

Figure 4: Effect of extractants on the extractability of HCT essential oil extracted by CGT. The series numbers of samples are the same as in Table 1.
3.2. Effect of Storage Time of the Extract on the Components in HCT Essential Oil

The storage of herbal medicine essential oil is equally important as its extraction. Decanoyl acetaldehyde is unstable and easily oxidized into decanoyl acetic acid and then decomposed into 2undecanone during storage [6]. Therefore, investigating the effect of storage time of the HCT extract on the volatile components is very meaningful. As shown in Figure 1 and Table 1, there was no obvious reduction in the content of the main components of the HCT extract using acetic ether as a solvent, such as decanoyl acetaldehyde, and its homologues with an increase in storage time, whereas the content slightly increased with a slight reduction in the content of 2undecanone. It is suggested that an inert environment is presented for storing HCT essential oil using acetic ether as a solvent, in which those predominant components of HCT essential oil can exist stably during storage. By contrast, the content of decanoyl acetaldehyde in HCT essential oil using ethanol as a solvent decreased remarkably when placed at room temperature for one day; further, the content of 2 undecanone decreased markedly during storage time from 1 day to 18 days. At the same time, a considerable content of decanoic acid (39.02\%), undecanoic acid (4.54\%), and dodecanoic acid (3.17\%) was observed and the decanoic acid was predominant in the mixture. This showed that decanoyl acetaldehyde and its homologues in HCT essential oil using ethanol as a solvent were oxidized to form the corresponding acids with an increase in storage time, instead of ketones, which was different from previous results $[6,8,13]$. Interestingly, decanoyl acetic ether $\left(t_{R}\right.$ $=27.42 \mathrm{~min}$ ) was found in the extract using ethanol as a solvent after storage of 18 days. Figure $\mathbf{5}$ shows the mass spectrum of decanoyl acetic ether obtained in this experiment and a reasonable explanation of its formed refragment ions.

Based on the above analysis, a possible mechanism for decompostion of decanoyl acetaldehyde in the extract is presented in Figure 6. At first, decanoyl acetaldehyde was oxidized to form decanoyl acetic acid, and then ethanol reacted with decanoyl acetic acid to form decanoyl acetic ether. Next, decanoyl acetic ether was decomposed into decanoic acid. A dynamic equilibrium between decanoyl acetic acid and 2-undecanone existed at room temperature. However, there was not enough power to produce any further 2-undecanone, due to the low temperature. Furthermore, the solvent with ethanol 


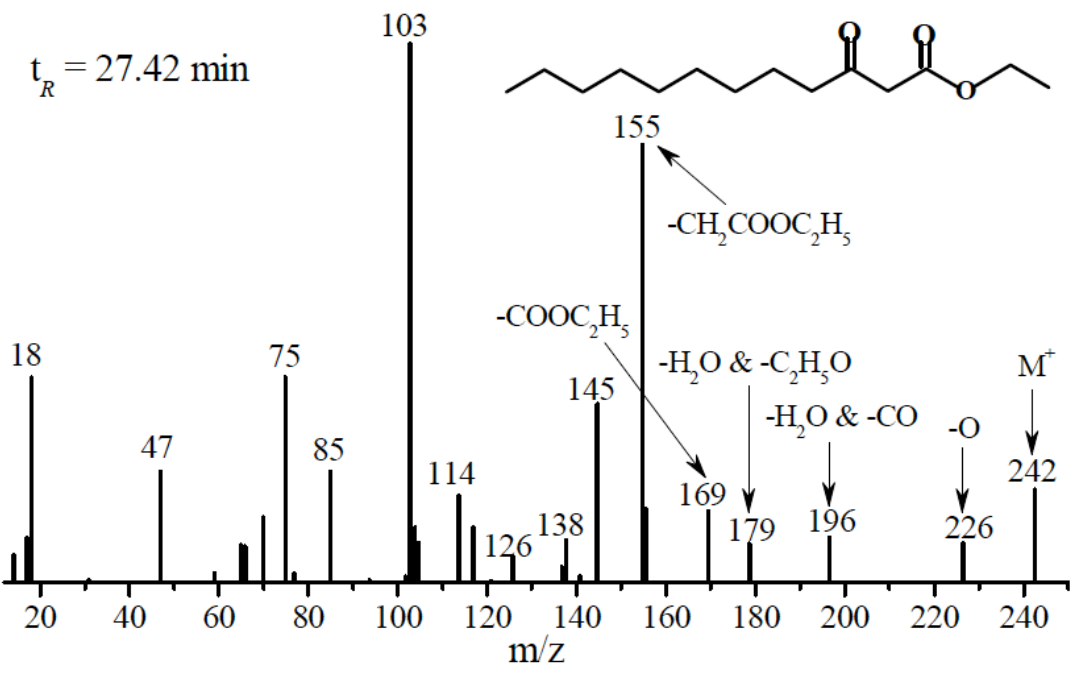

Figure 5: Mass spectra (EI, $70 \mathrm{eV}$ ) of HCT sample resolved by GC-MS at a retention time of $27.42 \mathrm{~min}$.
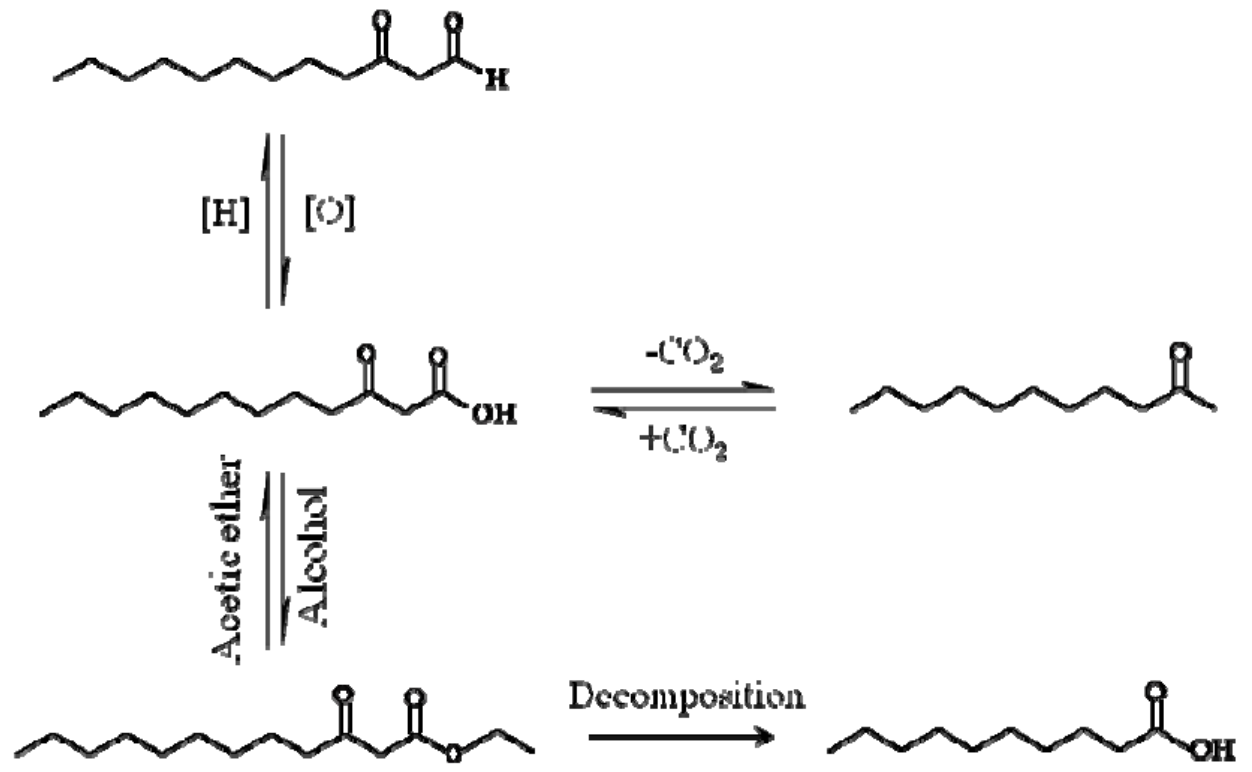

Figure 6: Illustration for transformation chemistry of decanoyl acetaldehyde.

as a promoter accelerated to form decanoyl acetic ether, resulting in predominant decanoic acid content from the decomposition of decanoyl acetic ether in the extract using ethanol as a solvent after storage of 18 days. The decrement in decanoyl acetic acid was replenished by the oxidation of decanoyl acetaldehyde at the beginning of the storage period, but this was not enough to produce decanoyl acetic acid from the decanoyl acetaldehyde with an increase in storage time. Accordingly, the dynamic balance between 2undecanone and decanoyl acetic acid was broken, resulting in an obvious decrease in 2-undecanone. A reverse process was promoted when a great deal of acetic ether was present in the extract. These results perfectly explain the phenomenon of decanoyl acetaldehyde being stable in the solvent with ethyl acetate but unstable in the solvent with ethanol during a long period of storage at room temperature.

\section{CONCLUSIONS}

A novel method was developed for highly efficient extraction of aromatic compounds from HCT by CGT. The extractability of the volatile compounds was as much as $1.14 \%$, while the content of decanoyl acetaldehyde in the extract was as high as $55.96 \%$ when ethyl acetate was used as an extractant. Furthermore, undenoyl acetaldehyde, dodenoyl acetaldehyde, and decyl-imine acetaldehyde were found for the first time. A possible mechanism for 
decomposition of decanoyl acetaldehyde in the HCT extract was presented. The solvent with ethanol as a promoter accelerated to form decanoyl acetic ether, whereas the reverse process was promoted when a significant amount of acetic ether was present in the extract. This study provided an accessible and convenient method for highly efficient extraction of aromatic compounds from HCT, especially suitable for extraction of those components that are unstable and easily oxidized at high temperatures. It was significant in the study of growth rhythm of HCT and providing further knowledge of the components of the volatile oil from HCT.

\section{REFERENCES}

[1] Lee JS, Kim IS, Kim JH, Kim JS, Kim DH, Yun CY. Suppressive effects of Houttuyniacordata thumb (saururaceae) extract on th2 immune response. J Ethnophsrmscol 2008; 117: 34-40. http://dx.doi.org/10.1016/j.jep.2008.01.013

[2] Li WF, Niu XF, Zhou P, Li M, He LC. A combined peritoneal macrophage/cell membrane chromatography and offline GCMS method for screening anti-inflammatory components from Chinese Traditional Medicine Houttuyniacordata thumb. J Chromatogr 2011; 73: 673-80. http://dx.doi.org/10.1007/s10337-011-1926-5

[3] Chiang LC, Chang JS, Chen DC, Ng LT, Lin CC. Anti-herpes simplex virus activity of bidens pilosa and Houttuynia cordata. Am J Chin Med 2003; 31: 355-62. http://dx.doi.org/10.1142/S0192415X03001090

[4] Chang JS, Chiang LC, Chen CC, Liu LT, Wang KC, Lin CC. Antileukemic activity of bidens pilosa L. var. minor (blume) sherff and Houttuynia cordata thumb. Am J Chin Med 2001; 29: 303-12.

http://dx.doi.org/10.1142/S0192415X01000320
[5] Chen YY, Liu JF, Chen CM, Chao PY, Chang TJ. A study of the antioxidative and antimutagenic effects of Houttuynia cordata Thunb. using an oxidized frying oil-fed model. J Nutr Sci Vitaminol (Tokyo) 2003; 49: 327-33. http://dx.doi.org/10.3177/jnsv.49.327

[6] Liang MM, Qi ML, Zhang CB, Zhou S, Fu RN, Huang JX. Gas chromatography-mass spectrometry analysis of volatile compounds from Houttuynia cordata thumb after extraction by solid-phase microextraction, flash evaporation and steam distillation. Anal Chim Acta 2005; 531: 97-104. http://dx.doi.org/10.1016/..aca.2004.09.082

[7] Qi M, Ge XX, Liang MM, Fu RN. Flash gas chromatography for analysis of volatile compounds from Houttuynia cordata thunb. Anal Chim Acta 2004; 527: 69-72. http://dx.doi.org/10.1016/j.aca.2004.08.073

[8] Zeng Z, Shi JG, Zeng HP, Lai WL. Application of organic mass spectrometry in studies on Houttuynia cordata, a Traditional Chinese Medicine. Chin J Anal Chem 2003; 31 399-404.

[9] Shimura M, Zhou Y, Asada Y, Yoshikawa T, Hatake K, Takaku F, et al. Inhibition of Vpr-induced cell cycle abnormality by quercetin: a novel strategy for searching compounds targeting Vpr. Biochem Biophys Res Commun 1999; 261: 308-16. http://dx.doi.org/10.1006/bbrc.1999.0994

[10] Murthy CT, Bhattacharya S. Cryogentic grinding of black pepper. J Food Eng 2008; 85: 18-28. http://dx.doi.org/10.1016/i.jfoodeng.2007.06.020

[11] Singh KK, Goswami TK. Design of a cryogenic grinding system for spices. J Food Eng 1999; 39: 359-68. http://dx.doi.org/10.1016/S0260-8774(98)00172-1

[12] Pruthi JS. Spices and condiments-Chemistry, Microbiology and Technology. Academic Press, New York 1980.

[13] Xue QS, Wang Z, Yin HR. Highly efficient extraction of decanoyl acetaldehyde in Houttuynia cordata thumb under steam distillation and its mass spectrometric analysis. J Anal Sci 2012; 28: 28-33.

[14] Xue QS, Yin HR. Highly efficient extraction of decanoyl acetaldehyde in Houttuynia cordata thumb under solvent immersing. J Anal Sci 2013; 29: 278.

Received on 15-11-2013

Accepted on 09-12-2013

Published on 31-12-2013

DOI: http://dx.doi.org/10.6000/1927-3037.2013.02.04.1

(c) 2013 Qing-Song Xue; Licensee Lifescience Global.

This is an open access article licensed under the terms of the Creative Commons Attribution Non-Commercial License (http://creativecommons.org/licenses/by-nc/3.0/) which permits unrestricted, non-commercial use, distribution and reproduction in any medium, provided the work is properly cited. 